\title{
Nutritional Status and Dietary Patterns of Thalassemia Patients at Selected Hospitals in Dhaka City, Bangladesh
}

ISSN: 2640-9208

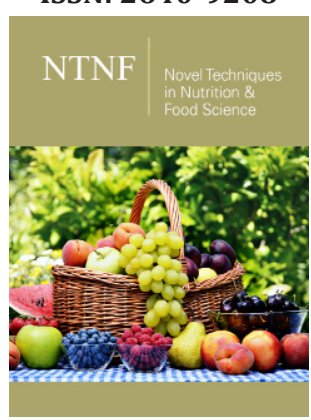

*Corresponding author: Shaidaton Nisha, MSc, Institute of Nutrition and Food Science, University of Dhaka, Bangladesh, Email: shaidatonnishaprova@gmail.com; Tel: +8801679480527

Submission: 誹 August 14, 2020

Published: 制 September 23, 2020

Volume 5 - Issue 2

How to cite this article: Shaidaton Nisha, Syeda Saima Alam, Md. Nahian Rahman and Khaleda Islam. Nutritional Status and Dietary Patterns of Thalassemia Patients at Selected Hospitals in Dhaka City, Bangladesh. Nov Tech Nutri Food Sci. 5(2). NTNF. 000607. 2020.

DOI: 10.31031/NTNF.2020.05.000607

Copyright@ Shaidaton Nisha. This article is distributed under the terms of the Creative Commons Attribution 4.0 International License, which permits unrestricted use and redistribution provided that the original author and source are credited.
Shaidaton Nisha ${ }^{1}$, Syeda Saima Alam² ${ }^{2}$ Md.Nahian Rahman ${ }^{1}$ and Khaleda Islam ${ }^{3}$

${ }^{1} \mathrm{MSc}$, Institute of Nutrition and Food Science, University of Dhaka, Bangladesh

${ }^{2}$ Lecturer, Department of Food Technology and Nutrition Science, Noakhali Science and Technology University, Bangladesh

${ }^{3}$ Professor, Institute of Nutrition and Food Science, University of Dhaka, Bangladesh

\begin{abstract}
The aim of the study is to assess the dietary patterns along with nutritional status of thalassemia patients at selected hospitals in Dhaka city. A cross sectional study was conducted among patients with thalassemia aged 18 to 40 years at Bangladesh Thalassemia Samity Hospital and Thalassemia hospital and institute in Dhaka city. The study assessed nutritional status by height, weight and BMI along with dietary and morbidity pattern of thalassemia. Among study population $7.7 \%$ male and $5.5 \%$ female had thalassemia major, $23.1 \%$ male and $40 \%$ female had thalassemia minor, $53.8 \%$ male and $45 \%$ female had thalassemia intermedia. Again $15.4 \%$ male as well as $46 \%$ female had Haemoglobin H. $33.3 \%$ of thalassemic patients were severely thin, $29.1 \%$ were moderately thin, $20.8 \%$ were mildly thin and $1.67 \%$ were normal in comparison of weight to height. Our research observed food consumption score and individual dietary diversity score among the patients and found that $35.8 \%$ of patients consumed acceptable low food diet, $32.5 \%$ consumed borderline food diet and only $6.7 \%$ of patients consumed acceptable high food diet. In case of individual dietary diversity score only $8.7 \%$ of patients consumed highly diversified food as various type of foods are restricted to the patients with thalassemia that ultimately leads to poor nutritional status. This study found that about $40 \%$ of patients with thalassemia were severely thin and surprisingly there were no patients with overweight. This revealed that patients with thalassemia are more vulnerable to survive as they cannot eat diversified food because of disease restriction.
\end{abstract}

Keywords: Nutritional status; Dietary patterns;Thalassemia patients; Bangladesh

\section{Introduction}

Thalassemia is emerging as a global public health concern. An estimated 320,000 babies are born each year with a clinically significant hemoglobin disorder [1]. Nearly $80 \%$ of these births occur in developing countries. Most conservative estimates suggest that at least $5.2 \%$ of the world population (over 360 million) carry a significant hemoglobin variant [1] and in excess of 100 million beta thalassemia carriers with a global frequency of $1.5 \%$ [2]. Thalassemia is a common problem in Bangladesh. According to World Health Organization (WHO) about 4.8 million people in Bangladesh are now carrying the gene of this silent killer disease, which is four per cent of the total population of the country. It is estimated that approximately 6000 babies with different types of thalassemia are born in Bangladesh each year [3]. Bangladesh is one of the most densely populated countries in the world, with a population of over 160 million people. Over $70 \%$ of the population live in highly resourceconstrained rural areas [4], while most tertiary hospitals are located in big cities, notably in Dhaka, the capital city. Public hospitals are often overcrowded and lack resources (such as specialized and basic medical equipment, healthcare professionals and essential drugs) [5]. On the contrary, some private clinics and hospitals are relatively resourceful, but these are not accessible to the general population due to the associated costs. The treatment drop-out rate among a population plagued by poverty is expected to be very high, and is presumably driven by lack of access, either due to lack of awareness or income of patients seeking care on the demand side, or inadequate expertise, facilities, knowledge, and infrastructure from the supply side of health care. 
Despite the fact that Bangladesh lies in the world's thalassemia belt, the information on different aspects (epidemiology, clinical course, mortality, complications and treatment outcomes) of thalassemias is lacking. Malnutrition affects the growth, efficacy of treatments and quality of life in patients suffering from thalassemia. Nutritional deficiencies are common in thalassemia, due to haemolytic anaemia, increased nutritional requirements, and morbidities. Thalassemia is a chronic disease that presents a range of serious clinical and psychological challenges. The effects of thalassemia on physical health can lead to physical deformity, growth retardation, and delayed puberty [6]. Its impact on physical appearance e.g., bone deformities and short stature, also contributes to a poor self-image [7]. About $61.3 \%$ of the adolescent consumed medium dietary diversified food. $30 \%$ of the respondent consumed lowest dietary diversified food where $8.7 \%$ girls consumed highly diversified food [8].

The aim of the study is to assess the dietary patterns along with nutritional status of thalassemia patients at selected hospitals in Dhaka city. Thalassaemia is the most common congenital disorder in Bangladesh. It is estimated that nearly 14,000 thalassaemia children are born every year in Bangladesh. Treatment facilities are limited due to the high cost of medicine and limited availability of blood for transfusion. Furthermore, medicines are not available readily other than in specialised thalassaemia centres in Dhaka and Chittagong. As treatment is expensive and lifelong, majority of the patients hardly afford proper treatment and thus suffer from the complications of the disease. Therefore, prevention is the fundamental way of uprooting thalassemia disease through knowledge dissemination. But where the disease already exists there is no option to prevent but curing becomes essential to make the life sustainable. So, to get acquainted with the usual dietary intake pattern, nutritional status and the usual morbidity pattern both physiological and psychological is a way through which a thalassemia patient go may be good factor to make the life more comfortable and sustainable for a thalassemia a patient.

\section{Methodology}

Methodology simply refers to a way of doing research or should the way to proceed. It is a structure of approaches and methods which are employed by researchers.

a) Type of study: The study was a descriptive cross-sectional study.

b) Data sources: The study was mainly based on primary data, however prior to collect primary data, relevant document was reviewed and collected.

c) Study population: The study was conducted among 120 thalassemia patients (not less than 18 years) in the selected hospitals in Dhaka city.

d) Places of study: The study was conducted in Bangladesh Thalassemia Samity Hospital and Thalassemia hospital and institute by frequent visiting.

e) Time period: December 25, 2018 to June 30, 2019. f) Sampling method: Random sampling

g) Sample size determination: Sample size has been calculated using following formula: -

$\mathrm{n}=\mathrm{z}^{2} \mathrm{pq} / \mathrm{d}^{2}$

Where $\mathrm{Z}=1.75$ at $92 \%$ confidence interval

$\mathrm{P}=50 \%=0.5 ; \mathrm{q}=1-\mathrm{P}=0.5 ; \mathrm{d}=$ Acceptable error $=8 \%=0.08$

$\mathrm{n}=\mathrm{z}^{2} \mathrm{pq} / \mathrm{d}^{2}$

$=(1.75)^{2 *}(.5) *(0.5) /(0.8) *(0.08)=119$

For the study a sample of 120 patients will be randomly selected to collect information on the proposed study. A pre-coded, clarified and pre-tested questionnaire is formulated to collect information from the patients.

\section{Sampling Selection Criteria}

\section{Inclusion criteria}

a) The respondents must be thalassemia patient age with age not less than 18 years.

b) The respondents must be among admitted patients in the hospitals.

c) Apparently willing to participate.

The respondent satisfying the above condition were randomly selected to form a sample size of 120 . A pre-coded, clarified and pre-tested questionnaire was formulated to collect information from the selected respondent.

\section{Exclusion criteria}

a) Not willing to participate in the study

b) Refusal from the family.

c) Demand money to participate.

\section{Pronouncement of consent}

The purpose and nature of the study were explained to each participant and after getting the verbal consent, they were included in the study.

\section{Data processing}

The data set was first checked, scrutinized, cleaned and entered into the computer from the numerical codes on the form. The data was edited to check if there was any discrepancy (double entry, wrong entry). The frequency distribution of the entire variable was checked using SPSS 23 windows program. It gave overall information about the variables. For purposive data analysis the raw anthropometric data of SPSS 23 windows program for further analysis. The new variables were recommended based on the analysis such age, education, income etc. After summarizing the collected data for each of the suggested indicators to answer the questions on the objectives of the study, the analysis was preceded according to the plan. 


\section{Ethical issue}

All participants in the study were asked for their consent before collection of data and venous blood, and all had complete rights to withdraw from the study at any time without any threat or disadvantage. Any participants with high blood pressure or other disorders were referred to appropriate facilities for further investigation and treatment. This study protocol was approved by the Ethical Review Committee of Bangladesh Medical Research Council (BMRC), Dhaka, Bangladesh. Informed written consent was taken from every subject. The questionnaire was designed considering the privacy of the subject. The subject's personal information was kept confidential.

\section{Data analysis}

Both qualitative and quantitative aspects of data were analysis followed descriptive to inferential statistics. Different types of variables were taken to see the association by using statistics such as to examine relationships among nutritional status, dietary diversity, food adequacy etc.

Table 1: Certain characteristics of the study subjects with thalassemia.

\begin{tabular}{|c|c|c|}
\hline Characteristics & $N=120$ & Percentage \\
\hline $\begin{array}{c}\text { Sex } \\
\text { Male } \\
\text { Female }\end{array}$ & $\begin{array}{l}65 \\
55\end{array}$ & $\begin{array}{l}54 \% \\
46 \%\end{array}$ \\
\hline $\begin{array}{c}\text { Relative's history } \\
\text { Yes } \\
\text { No }\end{array}$ & $\begin{array}{l}80 \\
40\end{array}$ & $\begin{array}{l}66.67 \% \\
33.33 \%\end{array}$ \\
\hline $\begin{array}{l}\text { Religion } \\
\text { Muslim } \\
\text { Hindu }\end{array}$ & $\begin{array}{l}88 \\
32\end{array}$ & $\begin{array}{c}73.3 \% \\
27 \%\end{array}$ \\
\hline $\begin{array}{l}\text { Marital status } \\
\text { Married } \\
\text { unmarried }\end{array}$ & $\begin{array}{l}85 \\
35\end{array}$ & $\begin{array}{l}70.8 \% \\
29.1 \%\end{array}$ \\
\hline $\begin{array}{c}\text { Economic burden (income in taka) } \\
<5000 \\
5000-10000 \\
>10000\end{array}$ & $\begin{array}{c}5 \\
85 \\
30\end{array}$ & $\begin{array}{c}4.2 \% \\
70.8 \% \\
25 \%\end{array}$ \\
\hline
\end{tabular}

Table 2: Distribution of thalassemia by sex and types of thalassemia.

\begin{tabular}{|c|c|c|c|}
\hline \multirow{2}{*}{ Characteristics } & \multicolumn{2}{|c|}{ sex } & \multirow{2}{*}{ Total } \\
\cline { 2 - 3 } & Male & female & \multirow{2}{*}{$8(6.67 \%)$} \\
\hline $\begin{array}{c}\text { Thalassemia } \\
\text { Major }\end{array}$ & $5(7.7 \%)$ & $3(5.5 \%)$ & \\
\hline $\begin{array}{c}\text { Thalassemia } \\
\text { Minor }\end{array}$ & $15(23.1 \%)$ & $22(40 \%)$ & $37(30.8 \%)$ \\
\hline $\begin{array}{c}\text { Thalassemia } \\
\text { Intermedia }\end{array}$ & $35(53.8 \%)$ & $25(45 \%)$ & $60(50 \%)$ \\
\hline $\begin{array}{c}\text { Haemoglobin } \\
\text { H }\end{array}$ & $10(15.4 \%)$ & $5(9.1 \%)$ & $15(12.5 \%)$ \\
\hline Total & $65(54.2 \%)$ & $55(46 \%)$ & $120(100 \%)$ \\
\hline
\end{tabular}

Table 1 shows the number of thalassemic patients based on certain characteristics such as sex, relative's disease history, religion, and income. Among study subjects 54\% were male and $46 \%$ were female. Relative's history of disease for positive response was $66.67 \%$ and for negative response was 33.3\%. $73 \%$ were Muslim and $27 \%$ were Hindu and their familial income below 5000 takas was $4.2 \%$, within 5000 to 10000 was $70.8 \%$ and above 10000 was $25 \%$. $70.8 \%$ of study patients were married and $29.2 \%$ were unmarried. The Table 2 shows the type of thalassemia based on sex. Among study population $7.7 \%$ male and 5.5\% female had thalassemia major, $23.1 \%$ male and $40 \%$ female had thalassemia minor, $53.8 \%$ male and $45 \%$ female had thalassemia intermedia. Again $15.4 \%$ male as well as $46 \%$ female had Haemoglobin H. Table 3 shows that $33.3 \%$ of thalassemic patients were severely thin, $29.1 \%$ were moderately thin, $20.8 \%$ were mildly thin and $1.67 \%$ were normal in comparison of weight to height. From the table, it is noticed that major portion of study population were undernourished which represent poor nutritional status of thalassemic patients. Again, it has been noticed that there is no occurrence of over-nutrition which reveals that thalassemia patients manifest underweight or undernutrition. Table 4 indicates $25 \%$ of patients' families were under poor consumption, 32.5\% were under borderline food consumption and $35.8 \%$ families fall in acceptable low food consumption whereas acceptable high food consumption covered only $6.7 \%$ of households. Figure 1 shows that about $61.3 \%$ of the patients consumed medium dietary diversified food. $30 \%$ of the respondent consumed lowest dietary diversified food where $8.7 \%$ patients with thalassemia consumed highly diversified food.

Table 3: Distribution of thalassemic patients in different categories of BMI.

\begin{tabular}{|c|c|c|}
\hline Category & Percentage & Frequency \\
\hline Severe thinness $\left(<16 \mathrm{~kg} / \mathrm{m}^{2}\right)$ & 33.3 & 40 \\
\hline Moderate thinness $(16-16.99)$ & 29.1 & 35 \\
\hline Mild thinness (17-18.49) & 20.8 & 25 \\
\hline Normal (18.5-24.99) & 1.67 & 20 \\
\hline Total & 100 & 120 \\
\hline
\end{tabular}

Table 4: Household food security status among study subjects with Thalassemia.

\begin{tabular}{|c|c|c|}
\hline Food Consumption Score & N=120 & Percentage \\
\hline Poor food consumption (0-28) & 30 & $25 \%$ \\
\hline Borderline food consumption (29-42) & 39 & $32.50 \%$ \\
\hline Acceptable low food consumption (43-52) & 43 & $35.80 \%$ \\
\hline Acceptable high food consumption (>53) & 8 & $6.70 \%$ \\
\hline Total & 120 & $100 \%$ \\
\hline
\end{tabular}




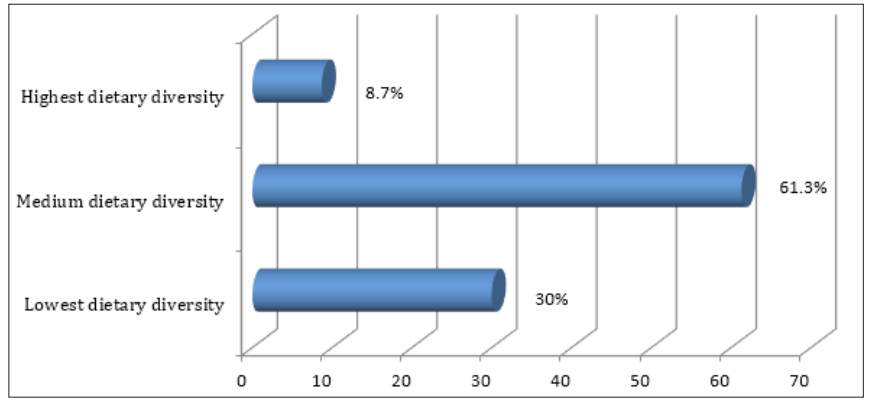

Figure 1: Diversity score of patients with thalassemia $(\mathrm{N}=120)$.

\section{Discussion}

Now-a-days, of the common inherited disorder, Thalassemia is becoming the most prevalent disorder among various groups of population in different parts of the world. In developing countries, it is one of the major health problems due to the lack of proper counselling, screening, diagnosis, and appropriate management. This study was done to identify the nutritional status, prevalence of thalassemia, dietary pattern of the patients. This study tried to show occupational profile with types of thalassemia such as Th Major, Th minor, Th intermedia, H Hemoglobin. Occupational profile shows that most of the thalassemia patients exhibit unemployed status which is an indicator of low working capability.

Again, this study indicates that maximum portion of family income is consumed in treatment than food allowances in case of thalassemia patients which puts financial burden for the families. Nutritional status of patients with thalassemia is a red flag as these patients deteriorate gradually and succumb to death. The findings of this study indicates that patients with thalassemia manifest underweight status as average height, weight and BMI of study patients with standard deviation that are $154.6 \pm 14(\mathrm{~cm})$, $40.5 \pm 9.9(\mathrm{~kg})$ and $18.3 \pm 4\left(\mathrm{~kg} / \mathrm{m}^{2}\right)$ respectively. Again $33.3 \%$ of thalassemic patients were severely thin, $29.1 \%$ were moderately thin, $20.8 \%$ were mildly thin and $1.67 \%$ were normal in comparison of weight to height and surprisingly there were no presence of overweight patients. This study also found that their positive association between low BMI and presence of disease.

Dietary pattern of thalassemia was observed by food consumption score and individual dietary diversity. In case of food consumption score $25 \%$ of patients' families were under poor consumption, $32.5 \%$ were under borderline food consumption and $35.8 \%$ families fall in acceptable low food consumption whereas acceptable high food consumption covered only $6.7 \%$ of households. Again, in case of individual dietary diversity score $61.3 \%$ of the patients consumed medium dietary diversified food, $30 \%$ of the respondent consumed lowest dietary diversified food where $8.7 \%$ patients with thalassemia consumed highly diversified food. In a recent research, about $61.3 \%$ of the adolescent consumed medium dietary diversified food. $30 \%$ of the respondent consumed lowest dietary diversified food where $8.7 \%$ girls consumed highly diversified food [8].

Low level of acceptable high food consumption in FCS and low level of highly diversified food consumption among thalassemia patients are due to restriction from certain types of food forbidden for the disease. Our study found no correlation between food consumption score and nutritional status (BAZ) and between individual dietary diversity score and nutritional status (BAZ). As nutritional status and health conditions among thalassemia patients are mainly determined by medication and routine-bound treatment.

\section{Conclusion}

The study finding indicates higher number of thalassemia patients attend tertiary-care center for regular blood transfusion and for treatment of other medical complications as most of the patients manifest morbid conditions. So, it is necessary to take it as a public health problem because thalassemia causes a huge psychological and financial drain on patients and their families. Thalassemia patients and their parents require life-long psychological support for prevention of mental health issues. Thus, the study tries to assess dietary pattern and nutritional status of the patients. Most of the respondents showed poor conditions of each criterion and their response to the intervention indicates that nutritional underweight contributes to growth failure in thalassemia. Proper use of iron chelation is safe and efficacious and should be made available, spending more time listening to patients in the clinic and perhaps including a psychologist in the multidisciplinary team to understand patients' individual needs might enhance adherence with medication.

\section{References}

1. Modell B, Darlison M (2008) Global epidemiology of haemoglobin disorders and derived service indicators. Bull World Health Organ 86(6): 480-487.

2. Colah R, Gorakshakar A, Nadkarni A (2010) Global burden, distribution and prevention of $\beta$-thalassemias and hemoglobin E disorders. Expert Rev Hematol 3(1): 103-117.

3. Khan WA (1999) Thalassaemia in Bangladesh. Dhaka Shishu (Children) Hospital Journal 15: 42-44.

4. (2013) The world factbook 2012-2013. Central Intelligence Agency, USA.

5. Islam A, Biswas $T$ (2014) Chronic non-communicable diseases and the healthcare system in Bangladesh: Current status and way forward. Chronic Dis Int 1(2): 6.

6. Telfer P, Constantinidou G, Andreou P, Christou S, Modell B, et al. (2005) Quality of life in thalassemia. Annals of the New York Academy of Sciences 1054(1): 273-282.

7. Caro JJ, Ward A, Levinton C, Robinson K (2002) The risk of diabetes during olanzapine use compared with risperidone use: a retrospective database analysis. The Journal of Clinical Psychiatry 63(12): 1135-1139.

8. Alam SS, Rahman N, Mia A, Haque M, Islam K (2018) Dietary diversity and nutritional status of adolescent girls in selected urban slum of Dhaka city in Bangladesh. Nutri Food Sci Int J 7(3): 555711. 